\title{
The Impact of Innovation on Profitability of Jordanian Services Companies
}

\author{
Khleef A. Alkhawaldeh ${ }^{1}$ \\ ${ }^{1}$ Part Time Lecturer, Dept. of Business Administration, PSUT, Jordan \\ Correspondence: Khleef A. Alkhawaldeh, Dept. of Business Administration, PSUT, Jordan. E-mail: \\ Khleef.k@gmail.com
}

Received: November 21, 2020

Accepted: December 18, 2020

Online Published: December 25, 2020

doi:10.5539/ijbm.v16n1p92

URL: https://doi.org/10.5539/ijbm.v16n1p92

\begin{abstract}
This research paper attempts to reveal the level of innovation types in Jordanian services companies. It also investigates the relationship between the overall innovation and profitability in these services companies. Innovation types have been measured through a questionnaire distributed to the members of Securities Depository Center SDC - Public Shareholding Companies - Service Sector. Profitability has been measured through the mean of net profits after taxes for the two years 2018 and 2019. The research findings indicate that innovation types in these companies is slightly below the average level. The results of research also indicate that there is a statistically significant positive impact of overall innovation on profitability of Jordanian services companies. The research concludes that investment in innovation is a key pillar for profitability of business companies.
\end{abstract}

Keywords: innovation, innovation types, Jordan, profitability, services companies

\section{Introduction}

Performance in terms of profitability varies from one company to another. During the last few years, many companies have achieved profits whereas the financial performance of other companies was negative. It is worth to know the nature of relationship between innovation and financial performance specifically profitability. Seeking new initiatives, means and tools on how to improve performance is a vital matter for business companies. This research paper aims to examine the level of innovation types in Jordanian services companies. Previous studies examined three types of innovation, such as product innovation, service innovation and process innovation (R. Lee, J. Lee \& Garretta, 2017; Crowley, 2017; Hanif \& Asgher, 2018; Verdu-Jover, Alos-Simo \& Gomez-Gras, 2018; Mahmoud, Hinson \& Anim, 2018; Rajapathirana \& Hui, 2018; Maier, 2018; Gustafsson, Snyder \& Witell, 2020; S. Najafi-Tavani, Z. Najafi-Tavani, Naudé, Oghazi \& Zeynaloo, 2020). In addition to the three types of innovation mentioned above, this research examines three new types of innovation, namely: system innovation, approach innovation and culture innovation. It also aims to investigate the impact of the overall innovation, which incorporates the six types of innovation, on profitability of these services companies.

\section{Literature Review}

Bartolacci, Paolini \& Zigiotti (2016) investigated the relationship between the number of patents registered and performance indicator trends, such as turnover and return on investment (ROI) and noticed a significant association between reduction in the average number of patents and worse performance. Cleven, Mettler, Rohner \& Winter (2016) affirmed that process orientation significantly enhances hospital performance in Switzerland.

Gomes \& Wojahn (2017) revealed that the organizational learning capability influences the innovative performance of small and medium-sized enterprises; however, the influence of the learning capability in organizational performance was not significant. Vekya (2017) indicated that there is a positive significant relationship between ATM transactions and bank profitability in Kenya $(p<0.05-0.004)$, and noticed that a unit increase in ATM transactions leads to an increase in ROE (bank profitability) by 1.662 units.

Marzi, Dabić \& Daim (2017) conducted a comprehensive overview of papers, authors, streams of research, and the most influential journals that discuss product and process innovation in the manufacturing environment. They reviewed a dataset composed of 418 papers from more than 150 journals from the period between 1985 and 2015 and highlighted five main areas of interests; namely, performance, patent, small firm, product development, and 
organization. Lee et al. (2017) indicated that exploration and exploitation orientations have positive impacts on product innovation and process innovation respectively, and process innovation encourages both radical and incremental product innovation. They also found that the relationship between a new product and company performance is increased with the introduction of marketing innovation in high-tech companies. Whereas, they revealed that process innovation has positive direct impacts on company performance with organizational innovation in the case of low-tech companies.

Crowley (2017) revealed that the factors affecting product innovation and discontinuation are similar for manufacturing and service firms, where innovation was significant for product/service discontinuation and process innovation was found to be important for innovation. Busru \& Shanmugasundaram (2017) revealed that research and development expenditure negatively affects the profitability but affects the profitability of subsequent years positively while taking lags. Witell et al. (2017) proposed four critical bricolage capabilities (addressing resource scarcity actively, making do with what is available, improvising when recombining resources, and networking with external partners) that affect the outcomes of service innovation.

Hanif \& Asgher (2018) indicated that there is a strong impact of multi-dimensional service innovation on service innovation performance, and each dimension of service innovation significantly predicts service innovation performance. Verdu-Jover et al. (2018) proposed that structural flexibility and reflexive learning positively affect the outcomes of product/service innovation by creating an adaptive culture. Mahmoud et al. (2018) unveiled that a service firm's ability to achieve customer satisfaction is dependent on how telecommunication operators harness and deploy their service innovation activities. In addition to that, they showed that customer value creation mediates the relationship between service innovation and customer satisfaction.

Rajapathirana \& Hui (2018) studied insurance companies in Sri Lanka and found a significant strong relationship between capabilities and efforts of innovation and performance of companies. They indicates that effective management of innovation capabilities help to deliver more effective innovation outcomes and thereby generate better performance. Kahn (2018) highlighted that innovation as a mindset addresses the internalization of innovation by individual members of the organization where innovation, is instilled and ingrained along with the creation of a supportive organizational culture that allows innovation to flourish. Maier (2018) mentioned that innovation has diverse materializations, includes product and technology renewal, and organizational changes, which may have an impact on quality, efficiency, improving the competitiveness and sustainability of the organization.

Oanh (2019) indicated that improving the types of innovation in enterprises affects the innovation performance of enterprises, and provided implications for business strategies based on innovation. Sujud and Hashem (2019) revealed that there is a significant positive impact of bank innovations on profitability and return on assets of Lebanese commercial banks. Xiea, Huob \& Zouc (2019) found that green process innovation has a positive impact on green product innovation, and that both green process innovation and green product innovation can improve financial performance.

YuSheng \& Ibrahim (2019) indicated that service innovation has direct influence on service delivery and customer satisfaction, and revealed a positive relationship between service delivery, customer satisfaction and bank customer loyalty. Mai, Vu, Bui \& Tran (2019) show that innovators achieve higher profit in comparison with non-innovating companies and mentioned that the benefits of innovation for profitability can be seen in higher export probability, better productivity, better access to formal credit, and the ability to secure government support, but only after innovation.

Gustafsson et al. (2020) indicated that there is no coherent theoretical framework that captures all the facets of service innovation. Najafi-Tavani et al. (2020) found a significant positive effect of collaborative innovation networks on product or process innovation capability in the presence of absorptive capacity. Udu, Agha, Anele \& Onunwor (2020) found that there is no significant relationship between generation of high quality products and profitability. They also found a significant relationship between use of new technologies and profitability and between value addition and higher profitability in manufacturing firms.

Most of previous studies focused on product innovation, service innovation and process innovation (Vekya, 2017; Marzi et al., 2017; Crowley, 2017; Witell et al., 2017; Verdu-Jover et al., 2018; . Kahn, 2018; Maier, 2018; Oanh, 2019; Xiea et al., 2019; Gustafsson et al., 2020; Najafi-Tavani et al., 2020). Previous studies also focused on the relationship between these three types of innovation (product innovation, service innovation and process innovation) and performance (Cleven et al., 2016; Vekya, 2017; . Lee et al., 2017; Busru \& Shanmugasundaram, 2017; Rajapathirana \& Hui, 2018; Oanh, 2019; Sujud \& Hashem, 2019; Xiea et al., 2019; YuSheng \& Ibrahim, 2019; Mai et al., 2019; Udu et al., 2020). This research proposes and focuses on three new types on innovation 
(system innovation, approach innovation and culture innovation) in addition to product innovation, service innovation and process innovation. It also reveals the nature of the relationship between the overall (integrated) innovation and profitability.

\section{The Theoretical Framework of the Research}

Innovation incorporates all activities and means used by companies to change or improve the products they produce, the services they perform and the way they produce products and perform services. Innovation could be radical (disruptive) or incremental (Lee et al., 2017; Marzi et al., 2017; Maier, 2018). Radical innovation means producing new products, performing new services and implementing new processes. Incremental innovation means improving and enhancing the current products, services and processes. Radical and incremental innovation aim to increase efficiency, effectiveness and the overall performance.

This research proposes several types of innovation, namely product innovation, service innovation, process innovation, system innovation, approach innovation and culture innovation. Product innovation indicates producing new products or developing the current products through the utilization of new technological trends and the activation of research and development engines (Marzi et al., 2017; Crowley, 2017; Verdu-Jover et al., 2018; Maier, 2018; Xiea et al., 2019; Najafi-Tavani et al., 2020). Service innovation refers to delivering completely new services or improving the current services through promoting and investing in new ideas and initiatives related to smart services, automation and digitalization (Vekya, 2017; Marzi et al., 2017; Hanif \& Asgher, 2018; Verdu-Jover et al., 2018; Mahmoud et al., 2018; Sujud \& Hashem, 2019; YuSheng \& Ibrahim, 2019; Gustafsson et al., 2020).

Process innovation means introducing new processes or enhancing the existing processes through simplified procedures, seamless processes, integrated and aligned processes (Cleven et al., 2016; Vekya, 2017; Marzi et al., 2017; Lee et al., 2017; Crowley, 2017; Xiea et al., 2019; Najafi-Tavani et al., 2020). System innovation stands for applying new systems or developing the existing systems, such as automated transparent live systems for performance management, effective systems for talents and human capital management, proactive attractive systems for customer relations management and other similar systems (Marzi et al., 2017; Gomes and Wojahn, 2017; Lee et al., 2017; Witell et al., 2017; Verdu-Jover et al., 2018; Maier, 2018; Najafi-Tavani et al., 2020; Udu et al., 2020).

Approach innovation relates to adopting a new management approach or enriching the adopted approach whether at the corporate, business units or markets levels (Marzi et al., 2017; Witell et al., 2017; Kahn, 2018; Maier, 2018; Oanh, 2019; Najafi-Tavani et al., 2020). Culture innovation concerns with creating a new work culture or refining the current culture through the deployment of the key concepts, principles and values of governance, integrity, transparency, excellence, resilience and agility (Marzi et al., 2017; Verdu-Jover et al., 2018; Kahn, 2018; Maier, 2018; Najafi-Tavani et al., 2020).

It is theoretically expected that the innovations types mentioned above contribute to performance of business companies through attracting potential customers and retaining the current customers and thereby increasing the profitability of these companies. Therefore, this research attempts to reveal the nature of the relationship between the overall innovation and profitability. This research consists of two types of variables. The independent variable is the overall innovation while the dependent variable is profitability. A schematic diagram for the conceptual research model is shown in Figure 2.

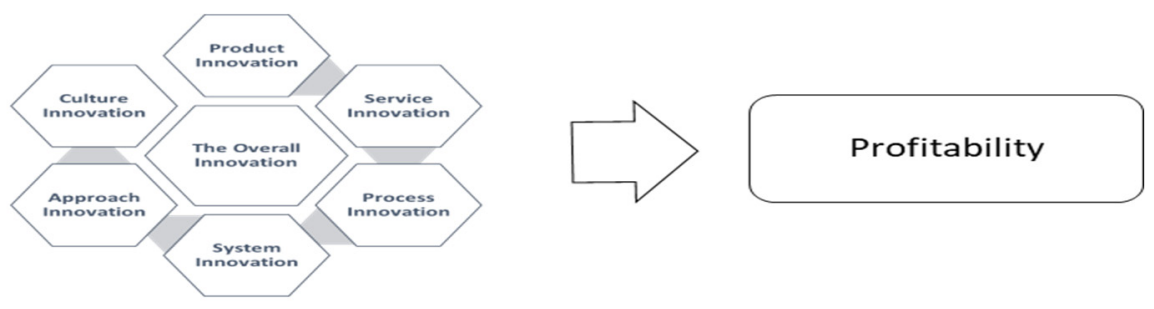

Figure 1. The study model

Two hypotheses developed and tested using appropriate statistical analysis techniques.

The first hypothesis: 
Ho: the overall innovation and all innovation types in Jordanian services companies are average level.

Ha: the overall innovation and all innovation types in Jordanian services companies are not average level

The second hypothesis

Ho: there is no statistically significant relationship between the overall innovation and profitability.

Ha: there is a statistically significant relationship between the overall innovation and profitability.

\section{Research Methodology}

The overall innovation consists of the six proposed types of innovation, namely: product innovation, service innovation, process innovation, system innovation, approach innovation and culture innovation. Innovation types have been measured through developing a questionnaire consisted of a set of questions. To ensure the validity of the developed questionnaire, it has been tested and then modified based on the feedback received from a number of experts in this regard. The final format of questionnaire has been distributed to the members of Securities Depository Center SDC - Public Shareholding Companies - Service Sector, the number of which is 140 companies. The measurement instrument scale is a 3-point scale: 1 for low level of innovation, 2 for average level of innovation and 3 for high level of innovation.

Profitability has been measured through the mean of net profits after taxes for the years 2018-2019. Net profits after taxes for the years 2018-2019 are published at the SDC website. The response rate was around $76 \%$ (106 companies). Therefore, the response rate is satisfactory to generate the results derived from the responding companies to the entire service sector. Reliability tested for the overall innovation using SPSS. The test output shows that the Cronbach's Alpha $=0.922$. This means that the reliability of responses on the questionnaire is high.

\section{Research Findings}

Descriptive statistics for innovation are shown in Table 1. As shown in Table 1, mean of the overall innovation = 1.6714 with standard deviation $=0.56506$. Means of all types of innovation are close to average level except mean of culture innovation, which is more close to low level than average level.

Table 1. Descriptive statistics - innovation

\begin{tabular}{llllll}
\hline Descriptive Statistics & $\mathrm{N}$ & Minimum & Maximum & Mean & Std. Deviation \\
\hline Product Innovation & 106 & 1.00 & 3.00 & 1.8019 & .72269 \\
Service Innovation & 106 & 1.00 & 3.00 & 1.8491 & .74056 \\
Process Innovation & 106 & 1.00 & 3.00 & 1.7925 & .73959 \\
System Innovation & 106 & 1.00 & 3.00 & 1.5189 & .58929 \\
Approach Innovation & 106 & 1.00 & 3.00 & 1.6132 & .67005 \\
Culture Innovation & 106 & 1.00 & 2.00 & 1.4528 & .50013 \\
The Overall Innovation & 106 & 1.00 & 2.67 & 1.6714 & .56506 \\
Valid N (list wise) & 106 & & & & \\
\hline
\end{tabular}

Outputs of one-sample $t$ test are shown in Table 2. Using test value $=2$ and as shown in Table 2, all sig. (2-tailed) values $<.05$, which means they are significant. This indicates that the overall innovation is below the average level but above low level. This supports the rejection of the first null hypothesis and the acceptance of the first alternate hypothesis in relation to the overall innovation. 
Table 2. Outputs of one-sample T-Test

One-Sample Test

Test Value $=2$

95\% Confidence Interval of the Difference

\begin{tabular}{lcccccc} 
& $\mathrm{t}$ & $\mathrm{df}$ & Sig. (2-tailed) & Mean Difference & Lower & Upper \\
\hline Product Innovation & -2.822 & 105 & .006 & -.19811 & -.3373 & -.0589 \\
Service Innovation & -2.098 & 105 & .038 & -.15094 & -.2936 & -.0083 \\
Process Innovation & -2.889 & 105 & .005 & -.20755 & -.3500 & -.0651 \\
System Innovation & -8.406 & 105 & .000 & -.48113 & -.5946 & -.3676 \\
Approach Innovation & -5.943 & 105 & .000 & -.38679 & -.5158 & -.2577 \\
Culture Innovation & -11.264 & 105 & .000 & -.54717 & -.6435 & -.4508 \\
The Overall Innovation & -5.988 & 105 & .000 & -.32862 & -.4374 & -.2198 \\
\hline
\end{tabular}

As shown in Table 3, mean of net profits for $63 \%$ of industrial companies was positive and for $37 \%$ of services companies was negative. Mean of net profits of $57 \%$ of companies is 5 million JD and less. Mean of net profits of $16 \%$ of the companies is higher than 5 million.

Table 3. Net income of industrial companies

\begin{tabular}{lcc}
\hline Mean of Net Profit (Thousand JD) & \# of Companies & $\%$ \\
\hline-1000 and less & 2 & $2 \%$ \\
Higher than -1000 - -500 & 8 & $8 \%$ \\
Higher than -500 - zero & 29 & $27 \%$ \\
Higher than zero - 1000 & 28 & $26 \%$ \\
Higher than $1000-5000$ & 23 & $21 \%$ \\
Higher than $5000-10000$ & 8 & $8 \%$ \\
Higher than 10000 & 8 & $8 \%$ \\
Total & 106 & $100 \%$ \\
\hline
\end{tabular}

As shown in Table 4, the outputs of dimension reduction (factor analysis) support the extraction of one component (the overall innovation) that includes all innovation types (product, service, process, system, approach and culture). Therefore, the relationship between the overall innovation and profitability has been tested using simple regression.

Table 4. Output of factor analysis

\begin{tabular}{|c|c|c|c|c|c|c|}
\hline \multicolumn{7}{|c|}{ Total Variance Explained } \\
\hline Component & Total & $\%$ of Variance & Cumulative \% & Total & $\%$ of Variance & Cumulative \% \\
\hline 2 & .641 & 10.681 & 84.260 & & & \\
\hline 3 & .371 & 6.178 & 90.438 & & & \\
\hline 5 & .186 & 3.101 & 98.450 & & & \\
\hline 6 & .093 & 1.550 & 100.000 & & & \\
\hline
\end{tabular}

Note. Extraction Method: Principal Component Analysis.

As shown in Table 5, Correlation $\mathrm{R}=.515, \mathrm{R}$ Squire $=.265$ and Adjusted $\mathrm{R}$ Squire $=.258$. This indicates that the relationship between the overall innovation and net profit is positive. It also indicates that coefficient of determination $\mathrm{R}^{2}=.265$, which means around $26 \%$ of change in mean of net profits can be explained by the change in the overall innovation (explained variance). 
Table 5. Outputs of regression test

\begin{tabular}{lllll}
\hline \multicolumn{2}{l}{ Model Summary } & & \\
\hline Model & $\mathrm{R}$ & $\mathrm{R}$ Square & Adjusted R Square & Std. Error of the Estimate \\
1 & $.515^{\mathrm{a}}$ & .265 & .258 & 7759.59042 \\
\hline
\end{tabular}

a. Predictors: (Constant), The Overall Innovation.

As shown in Table 6, the significance of the F-test value $=.000$, which reveals that there is a statistically significant positive relationship between the overall innovation and net profit. This indicates the positive impact of the overall innovation on profitability of Jordanian services companies, which supports the rejection of the second null hypothesis and the acceptance of the second alternate hypothesis.

Table 6. Outputs of ANOVA

\begin{tabular}{llccccc}
\hline \multicolumn{7}{c}{ ANOVA $^{\mathrm{a}}$} \\
\hline \multicolumn{1}{l}{ Model } & Sum of Squares & df & Mean Square & F & Sig. \\
\hline 1 & Regression & 2257394482.112 & 1 & 2257394482.112 & 37.491 & $.000^{\mathrm{b}}$ \\
& Residual & 6261969323.850 & 104 & 60211243.499 & & \\
& Total & 8519363805.962 & 105 & & & \\
\hline
\end{tabular}

a. Dependent Variable: Main of Net Profit

b. Predictors: (Constant), The Overall Innovation

\section{Results Discussion and Conclusion}

Based on the findings of this research, all types of innovation contribute to profitability and performance in general. The research findings concerning the relationship between innovation and profitability are supported in literature (Bartolacci et al., 2016; Vekya, 2017; Marzi et al., 2017; Lee et al., 2017; Hanif \& Asgher, 2018; Rajapathirana \& Hui, 2018; Sujud \& Hashem, 2019; Xiea et al., 2019; Mai et al., 2019; Udu et al., 2020). Integrated innovation or in other words overall innovation covers the following aspects: product, service, process, system, approach and culture. Innovation supports future shaping and enables the achievement and protection of market share. Profitability can be realized through optimizing resources and objectives (Maier, 2018; Mai et al., 2019). Therefore, innovation attempts, efforts and activities should target efficiency and effectiveness. Targeting efficiency to ensure the rational utilization of resources and targeting effectiveness to maximize performance results).

Innovation requires upgrading the way of thinking and planning followed by good implementation supported by monitoring and evaluation system that facilitates the learning and improvement in a continual basis (Kahn, 2018; Verdu-Jover et al., 2018; Najafi-Tavani et al., 2020). Globalization and electronic marketing are the key challenges facing business companies as competition move cross the boarders of countries. Customer is always looking for new value in his/her commercial dealings and transactions. What satisfies the customer today is not necessarily satisfies him/her tomorrow.

The research concludes that innovation is the true guarantee of business continuity. It is also the right mechanism or tool to create, maintain and sustain the competitive advantages through adding value to customers (Baggio \& Valeri, 2020; Valeri \& Baggio, 2020a; Valeri \& Baggio, 2020b). Resilience and Agility are necessary to predict and understand any changes in external and internal business environment factors and to be proactive in dealing with them and translate them into potential opportunities to benefit from in renewing the growth phase of business cycle. To be innovative in anything you do or behave is the best enabler for a steady sustained progress of business companies.

Innovation is the right pillar for companies to penetrate markets, grow and lead business. Leading and sustainable positions can be reached by companies through promoting innovative products, services, processes and the like initiatives. Therefore, companies should invest in radical innovation as much as its investments in incremental innovation. This research also proved that innovation is not limited to its known types related to products and services, but rather shapes all aspects of work in companies.

Enhancing innovative capabilities is the key driver of innovation activities and outcomes (Arcese, Valeri, Poponi \& Elmo, 2020; Elmo, Arcese, Valeri, Poponi \& Pacchera, 2020). Companies are recommended to pay more concentration on system innovation, approach innovation and culture innovation. For instance, modernizing 
business mindset and activating its machinery, and reengineering the way of running and managing business in addition to enriching work culture. These types of innovation contribute to the success of companies as like as traditional types. Future studies are recommended to be focused on the practices and impacts of approach innovation as a management approach and on culture innovation supported by related concepts, principles and values. It is also suggested for future research to examine the role of innovation in improving the institutional and operational performance including financial and nonfinancial performance.

\section{References}

Arcese, G., Valeri, M., Poponi, S., \& Elmo, G. (2020). Innovative drivers for Family business models in tourism. Journal of Family business Management. https://doi.org/10.1108/JFBM-05-2020-0043

Baggio, R., \& Valeri, M. (2020). Network science and sustainable performance of family businesses in tourism. Journal of Family Business Management. https://doi.org/10.1108/JFBM-06-2020-0048

Bartolacci, F., Paolini, A., \& Zigiotti, E. (2016). Innovation and Profitability in a Population of Italian Listed Companies during a Time of Crisis. Rivista Piccola Impresa/Small Business, 2. https://doi.org/10.14596/pisb.238.

Busru, S., \& Shanmugasundaram, G. (2017). Effects of Innovation Investment on Profitability and Moderating Role of Corporate Governance: Empirical Study of Indian Listed Firms. Indian Journal of Corporate Governance, 10(2) 97-117. https://doi.org/10.1177/0974686217730938

Cleven, A., Mettler, T., Rohner, P., \& Winter, R. (2016). Healthcare Quality Innovation and Performance through Process Orientation: Evidence from General Hospitals in Switzerland. Technological Forecasting and Social Change. https://doi.org/10.1016/j.techfore.2016.07.007

Crowley, F. (2017). Product and Service Innovation and Discontinuation in Manufacturing and Service Firms in

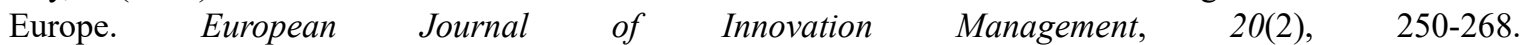
https://doi.org/10.1108/EJIM-03-2016-0027

Elmo, G., Arcese, G., Valeri, M., Poponi, S., \& Pacchera, F. (2020). Sustainability in tourism as innovation driver: an analysis of family business reality. Sustainability, 12(15), 6149. https://doi.org/10.3390/su12156149

Hanif, M., \& Asgher, M. (2018). Service Innovation and Service Innovation Performance: A Study of Banking Services. Pakistan Journal of Commerce and Social Sciences, 12(2), 670-694.

Gomes, G., \& Wojahn, R. (2017). Organizational learning capability, innovation and performance: study insmall and medium-sized enterprises (SMES). Revista de Administração, 52, 163-175.

Gustafsson, A., Snyder, H., \& Witell, L. (2020). Service Innovation: A New Conceptualization and Path Forward. Journal of Service Research, 1-5. https://doi.org/10.1177/1094670520908929

Kahn, K. (2018). Understanding innovation. Business Horizons, 61, 453-460.

Lee, R., Lee, J., \& Garretta, T. (2017). Synergy effects of innovation on firm performance. Journal of Business Research. http://dx.doi.org/10.1016/j.jbusres.2017.08.032

Maier, D. (2018). Product and Process Innovation: a New Perspective on the Organizational Development. International Journal of Advanced Engineering and Management Research, 3(6).

Marzi, G., Dabić, M., \& Daim, T. (2017). Product and Process Innovation in Manufacturing Firms - a Thirty-Year Bibliometric Analysis. Scientometrics, 113(2), 673-704.

Najafi-Tavani, S., Najafi-Tavani, Z., Naudé, P., Oghazi, P., \& Zeynaloo, E. (2018). How collaborative innovation networks affect new product performance: Product innovation capability, process innovation capability, and absorptive capacity. Industrial Marketing Management, 73, 193-205.

Mahmoud, M., Hinson, R., \& Anim, P. (2018). Service Innovation and Customer Satisfaction: the Role of Customer Value Creation. European Journal of Innovation Management, 21(3), 402-422. https://doi.org/10.1108/EJIM-09-2017-011

Mai, A., Vu, H., Bui, B., \& Tran, T. (2019). The Lasting Effects of Innovation on Firm Profitability: Panel Evidence from a Transitional Economy. Economic Research-Ekonomska Istraživanja, 32(1), 3417-3436. https://doi.org/10.1080/1331677X.2019.1660199

Oanh, N. (2019). The Relationship between Innovation Capability, Innovation Type and Innovation Performance in FDI Enterprises in Vietnam. International Journal of Economics and Finance; 11(8).

Rajapathirana, R., \& Hui, Y. (2018). Relationship between innovation capability, innovation type, and firm 
performance. Journal of Innovation \& Knowledge, 3, 44-55.

Securities Depository Center. (2020). SDM Members Information. Retrieved from http://www.sdc.com.jo

Sujud, H., \& Hashem, B. (2017). Effect of Bank Innovations on Profitability and Return on Assets (ROA) of Commercial Banks in Lebanon. International Journal of Economics and Finance, 9(4).

Udu, G., Agha, N., Anele, C., \& Onunwor, A. (2020). Innovation and Manufacturing Firms' Profitability. IOSR Journal of Business and Management, 22(6), 33-39. https://doi.org/10.9790/487X-2206053339

Valeri, M., \& Baggio, R. (2020a). Social network analysis: organizational implications in tourism management. International Journal of Organizational Analysis. https://doi.org/10.1108/IJOA-12-2019-1971

Valeri, M., \& Baggio, R. (2020b). Italian tourism intermediaries: a social network analysis exploration. Current Issues in Tourism. https://doi.org/10.1080/13683500.2020.1777950

Vekya, J. (2017). Impact of Electronic Banking on the Profitability of Commercial Banks in Kenya. Journal of Technology and Systems, 1(1), $18-39$.

Verdu-Jover, A., Alos-Simo, L., \& Gomez-Gras, J. (2018). Adaptive Culture and Product/Service Innovation Outcomes. European Management Journal, 36, 330-340.

Witell, L., Gebauer, H., Jaakkola, E., Hammedi, W., Patricio, L., \& Perks, H. (2017). A Bricolage Perspective on Service Innovation. Journal of Business Research, 79, 290-298.

Xiea, X., Huob, J., \& Zouc, H. (2019). Green process innovation, green product innovation, and corporate financial performance: A content analysis method. Journal of Business Research, 101, 697-706.

YuSheng, K., \& Ibrahim, M. (2019) Service innovation, service delivery and customer satisfaction and loyalty in the banking sector of Ghana, International Journal of Bank Marketing, https://doi.org/10.1108/IJBM-06-2018-0142

\section{Copyrights}

Copyright for this article is retained by the author(s), with first publication rights granted to the journal.

This is an open-access article distributed under the terms and conditions of the Creative Commons Attribution license (http://creativecommons.org/licenses/by/4.0/). 